Article

\title{
Speed Synchronous Control of Multiple Permanent Magnet Synchronous Motors Based on an Improved Cross-Coupling Structure
}

\author{
Wei Chen $*$ (), Jiaojiao Liang ${ }^{(\mathbb{D})}$ and Tingna Shi \\ School of Electrical and Information Engineering, Tianjin University, Tianjin 300072, China; \\ liangjia0jia0@tju.edu.cn (J.L.); tnshi@tju.edu.cn (T.S.) \\ * Correspondence: chen_wei@tju.edu.cn; Tel.: +86-022-2740-2325
}

Received: 1 January 2018; Accepted: 23 January 2018; Published: 24 January 2018

\begin{abstract}
Regarding the shortcomings of the cross-coupling control structure during the start-up of a multi-motor with load-namely, a large synchronization error and a long start-up time-this paper proposes a fuzzy self-adjusting cross-coupling control structure. This structure combines a fuzzy self-adjusting filter and an advanced synchronization compensator. The fuzzy self-adjusting filter adjusts the "softened speed", a newly established concept, so that each motor follows the trajectory of the softened speed during start-up, thus effectively reducing the synchronization error of the starting process. The advanced synchronization compensator is added to shorten the adjusting time of the motors. In addition, this paper analyzes the synchronization performance of the structure when the steady state is interrupted by a sudden step of load. Finally, this paper establishes an experimental platform for a synchronous speed control system for a permanent magnet synchronous motor, and verifies the effectiveness of the proposed structure and the correctness of the theoretical analysis through performing experiments.
\end{abstract}

Keywords: fuzzy self-adjusting filter model; softened speed; advanced synchronization compensator; cross-coupling control; speed synchronous control

\section{Introduction}

With the development of modern industry, the synchronous control of multi-motors has been widely used in robotics, electric vehicles, steel rolling, papermaking, and other fields [1-8]. Shortening the start-up time and improving the synchronization performance of multi-motors are of both theoretical and practical significance for enhancing the control accuracy and stability of the system [9-15].

A virtual line-shafting control and a cross-coupling control structure are usually adopted in the traditional multi-motor synchronous control [16-20]. Anderson R.G. et al. [21] proposed the concept of "electronic virtual line-shafting". The sum of electromagnetic torque from the servo motors was taken as the load torque of the main motor, which can reduce the synchronization error caused by the starting delay, but the starting time was longer. Therefore, it's not applicable to the occasions that require a high starting performance. Then, Koren Y. et al. presented a cross-coupling control structure, where the speed difference between two motors was taken as a feedback. This structure could better reflect the load changes of each motor [22], so, it exhibits good synchronization performance in the steady-state operation. In order to improve the synchronization performance and tracking performance of a multi-motor system under sudden changes of load during steady operation, Gu X., Zhang H. and Liu G. et al. presented [23-25] many advanced control methods, such as a neural network, sliding mode control, and internal model control are applied to the cross-coupling control. However, the 
above methods still have the shortcomings of a large synchronization error and a long starting time during the start-up of a loaded multi-motor system.

Aiming at the aforementioned problems, this paper presents a fuzzy self-adjusting cross-coupling control structure that combines a fuzzy self-adjusting filter with an advanced synchronization compensator. The concept of "softened speed" is put forward in this new structure. The fuzzy controller adjusts the softened coefficient of each motor smoothly according to the load torque and the actual given speed; therefore, the softened speed can be adjusted automatically. In this way, motors can follow the trajectory of the softened speed during the start-up of a multi-motor with load, and thus reduce the synchronization error. At the same time, the advanced synchronization compensator is put forward to utilize the phase advance characteristic and obtain the phase advance, thus shortening the adjusting time of the motors. Finally, the experimental platform of the synchronous speed control system is established, and the effectiveness of the fuzzy self-adjusting cross-coupling control structure proposed in this paper is verified through experiments.

\section{Traditional Cross-Coupling Control}

The control method, which adopts speed difference as a compensation signal in multi-motor synchronous control, holds high reliability [26]. The speed difference between the two motors is taken as a compensation signal in the traditional cross-coupling control method. The compensation signal can reduce the speed error of the two motors when the motor is disturbed internally or externally $[27,28]$. The motion equations of a permanent magnet synchronous motor (PMSM) are taken to describe the dynamic and static performance of two motors in the cross-coupling control structure [29]:

$$
\left\{\begin{array}{l}
J \frac{\mathrm{d} \omega}{\mathrm{d} t}=T_{\mathrm{e}}-T_{\mathrm{L}}-B \omega \\
T_{\mathrm{e}}=K_{\mathrm{T}} i_{\mathrm{q}}
\end{array}\right.
$$

where $J$ is the moment of inertia of the motor; $\omega$ is the rotor angular velocity of the motor; $T_{\mathrm{e}}$ is the electromagnetic torque; $T_{\mathrm{L}}$ is the load torque; $K_{\mathrm{T}}$ is the torque coefficient; and $B$ is the damping coefficient.

For the convenience of analysis, the motor is usually equivalent to an integral part, disregarding the delay of the current loop and speed measurement. The block diagram of the traditional cross-coupling control structure is shown in Figure 1.

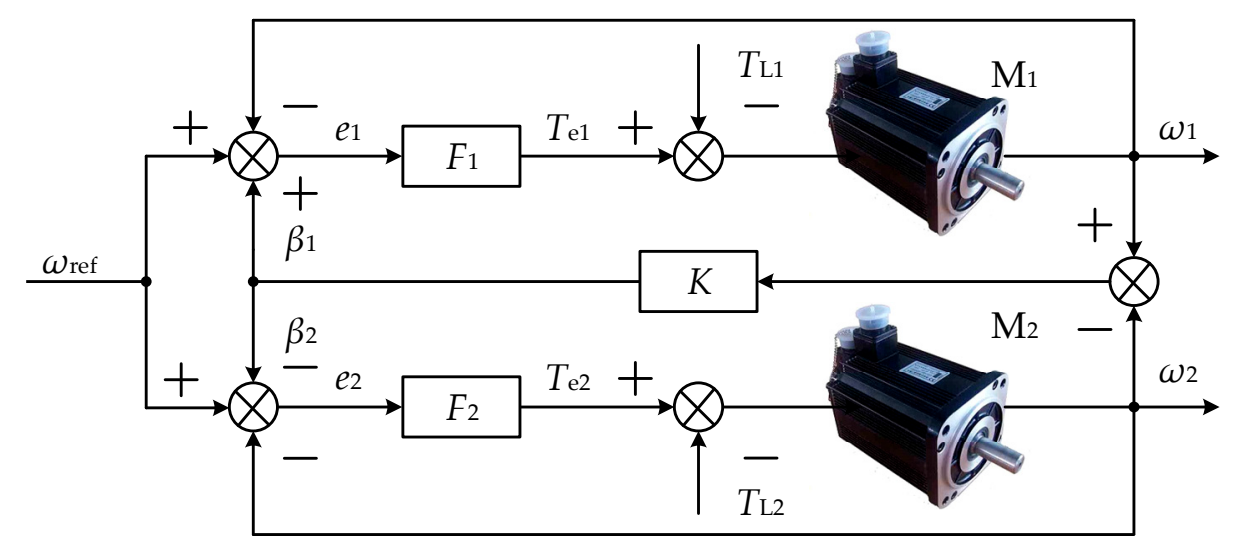

Figure 1. Traditional cross-coupling control structure.

In Figure $1, \omega_{\text {ref }}$ is the given speed of two motors; $T_{\mathrm{L} i}(i=1,2)$ is the load torque of the $i$ th motor; $\omega_{i}$ is the output speed of the $i$ th motor; and the equivalent transfer function of the $i$ th motor $\mathrm{M}_{i}$ is given by:

$$
G_{i}(s)=\frac{1}{J_{i} s}
$$


where $F_{i}$ is the $i$ th motor speed loop controller; the structure is shown in Figure 2.

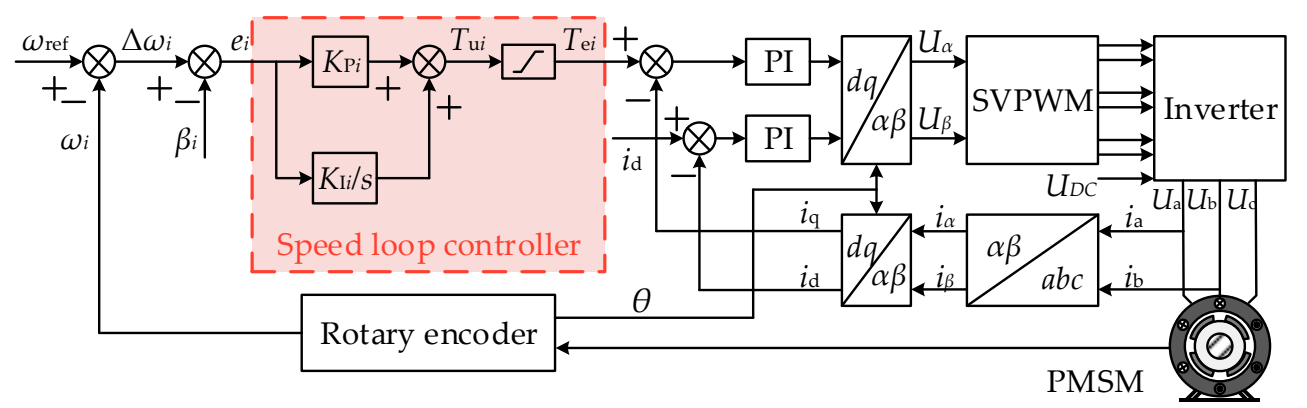

Figure 2. Control system of double closed-loop permanent magnet synchronous motor (PMSM).

In Figure 2, $T_{\mathrm{u} i}$ is the amplitude-unlimited electromagnetic torque output of the $i$ th motor; $T_{\mathrm{e} i}$ is the amplitude-limited electromagnetic torque output of the $i$ th motor; and $e_{i}$ is the input of speed loop controller of the $i$ th motor, which can be expressed as:

$$
e_{i}=\Delta \omega_{i}-\beta_{i}
$$

where $\Delta \omega_{i}$ is the tracking error of the $i$ th motor; and $\beta_{i}$ is the compensation value. $\beta_{i}$ is given by:

$$
\beta_{i}=K\left(\omega_{i}-\omega_{j}\right) \quad i \neq j, i=1,2
$$

where $K_{i j}$ is the synchronous compensation coefficient between two motors.

Taking the $i$ th motor as an example, the speed loop controller $F_{i}$ can be expressed as:

$$
F_{i}=K_{\mathrm{P} i}+\frac{K_{\mathrm{I} i}}{\mathrm{~s}}
$$

In Equation (5), the proportional coefficient $K_{\mathrm{P} i}$ and the integral coefficient $K_{\mathrm{I} i}$ need to be adjusted according to the dynamic and static performance of the speed loop. $K_{\mathrm{P} i}$ and $K_{\mathrm{I} i}$ are shown in Equation (6).

$$
\left\{\begin{array}{l}
K_{\mathrm{P} i}=f_{\mathrm{c}} J_{i} \\
K_{\mathrm{I} i}=\left(\frac{f_{\mathrm{c}}}{2 \varsigma}\right)^{2} J_{i}
\end{array}\right.
$$

where $f_{\mathrm{c}}$ and $\zeta$ are the bandwidth and damping coefficient of the speed loop, respectively. Each motor is set by the above method [30], hence:

$$
F_{i}(s) \cdot G_{i}(s)=F(s) \cdot G(s)=\frac{f_{\mathrm{c}}}{s}+\frac{\left(f_{\mathrm{c}}\right)^{2}}{(2 \varsigma s)^{2}}
$$

Which means that each motor has the same open-loop transfer function, independently of the moment of inertia.

There are some shortcomings in a traditional cross-coupling control structure during the start-up of a multi-motor with load:

1. In Figure 2, the tracking error $\Delta \omega_{i}$ is much larger than the compensation value $\beta_{i}$, according to Equation (3), and $e_{i}$ is very large during the start-up of a multi-motor with load, thus making the amplitude-unlimited output of electromagnetic torque $T_{u i}$ much larger than the saturation value. However, the output of the speed loop controller generally contains a limiting part because of the system's safety requirements. The output $T_{\mathrm{e} i}$ of the speed loop controller will be saturated for a period of time, during which the compensation value does not work, eventually leading to a larger synchronization error. 
2. When the speed fluctuation of the system is large, the fixed gain compensation can't be adjusted according to the disturbance of each motor in real time; this results in a longer adjusting time.

\section{Fuzzy Self-Adjusting Cross-Coupling Control}

Aiming at the problem of the cross-coupling control structure in the start-up of a multi-motor system with load, this paper adds a fuzzy self-adjusting control module, and introduces the advanced synchronous compensator into the traditional cross-coupling control structure. The block diagram of the two motors is shown in Figure 3.

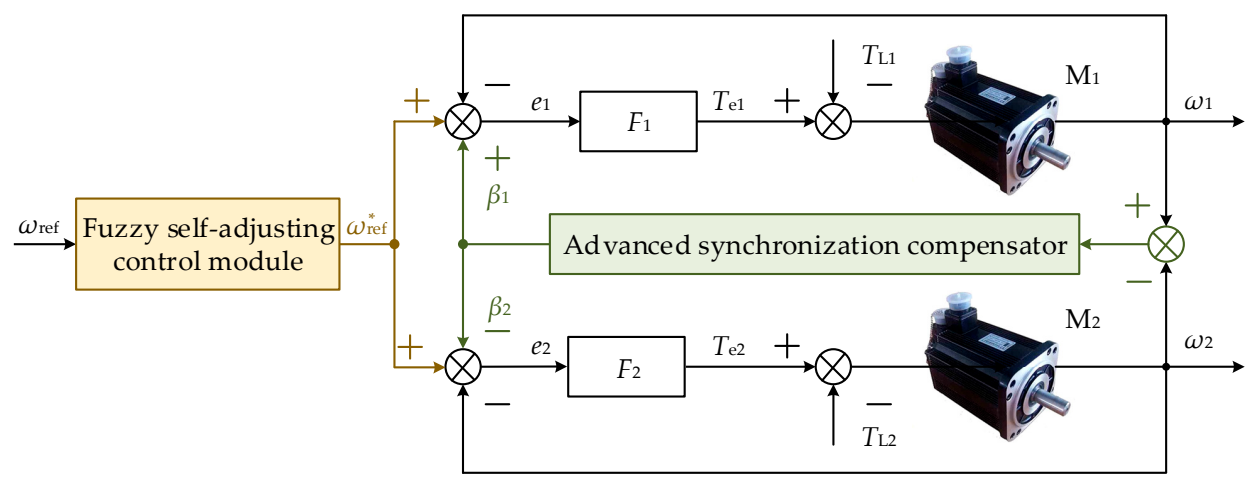

Figure 3. Fuzzy self-adjusting cross-coupling control structure.

The fuzzy self-adjusting control module and advanced synchronization compensator module are discussed as follows.

\subsection{Fuzzy Self-Adjusting Control Module}

Since the tracking error is much larger than the compensation value in the cross-coupling control structure during the start-up of a multi-motor with load, $T_{\mathrm{e} i}$ is in saturation for a long time, thus resulting in a greater synchronization error. In a fuzzy self-adjusting cross-coupling control structure, the softened speed $\omega^{*}$ ref is adjusted by the fuzzy self-adjusting control module, which makes it converge to $\omega_{\text {ref }}$ smoothly. This makes the tracking error close to the output of the synchronous compensator in the starting process, thus reducing the influence of the saturation of the limiting part of the speed loop controller on the synchronization error. The fuzzy self-adjusting control module is shown in Figure 4.

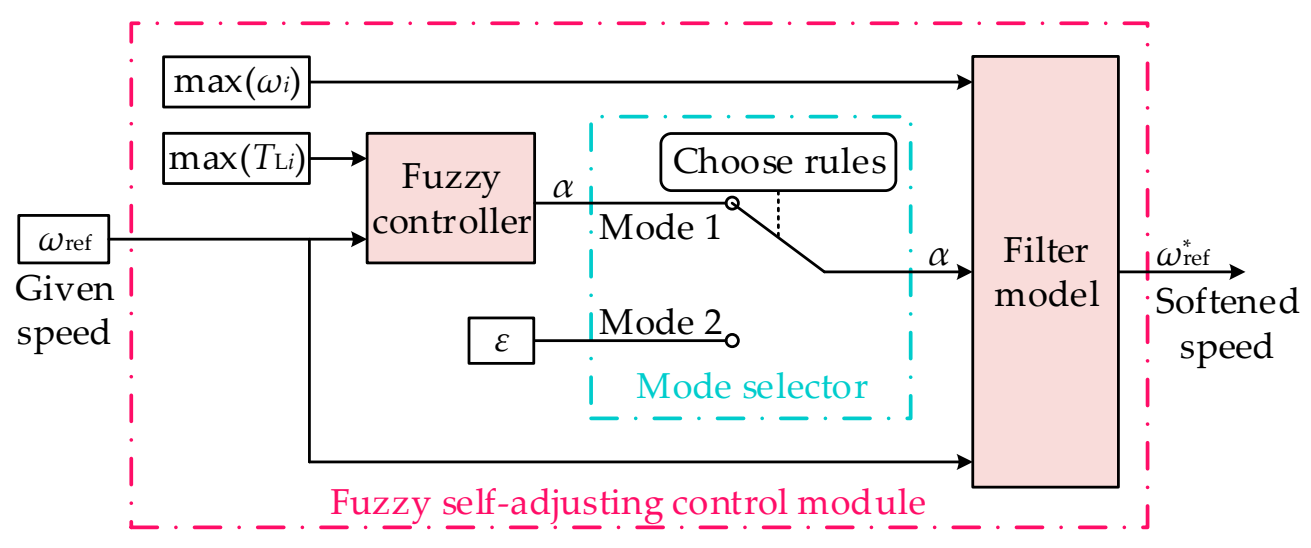

Figure 4. Fuzzy-self-adjusting control module. 
In Figure 4, the output $\alpha$ of the fuzzy controller is defined as the softened coefficient, and $\varepsilon$ is defined as the steady state control coefficient. In this paper, $\varepsilon=1$. Namely:

$$
\left\{\begin{array}{l}
\omega_{\max }=\max \left\{\omega_{1}, \omega_{2}\right\} \\
T_{\mathrm{Lmax}}=\max \left\{T_{\mathrm{L} 1}, T_{\mathrm{L} 2}\right\}
\end{array}\right.
$$

The mode selector is used to switch between modes. It divides the fuzzy controller into two operating modes based on $\omega_{\max }$. Mode 1: when $\omega_{\max }<0.98 \omega_{\text {ref }}$, it is considered that the motor is in a fast start stage. The fuzzy controller and the filter work simultaneously, so that each motor follows the trajectory of the softened speed to reduce the synchronization error; Mode 2: when $\omega_{\max } \geq 0.98 \omega_{\text {ref, }}$, it is considered that the motor gradually enters into the steady state. In this case, only the filter is activated, thereby improving the dynamic response of the system.

In order to make the softened speed transition to the set value at a certain response speed smoothly, the following filter link is usually taken $[31,32]$ :

$$
\omega_{\text {ref }}^{*}=\alpha \omega_{\text {ref }}+(1-\alpha) \omega_{\max }
$$

where $0<\alpha<1$.

Selecting $\omega_{\text {ref }}=1000 \mathrm{r} / \mathrm{min}$, the load torque of two motors during the start-up are $T_{\mathrm{L} 1}=5 \mathrm{~N} \cdot \mathrm{m}$, and $T_{\mathrm{L} 2}=0$, respectively. Take $\alpha \in(0,1)$ as input; the output are the adjusting time $t_{\mathrm{s}}$ of Motor 1 and the synchronization error $\Delta \omega$ between the two motors. When the parameters, such as the given speed and load torque remain unchanged, the influence of the change of the coefficient $\alpha$ on the synchronization error and adjusting time of the system can be described by several rounds of simulation. As can be seen in Figure 5, the synchronization error and adjusting time of each motor during start-up are affected by the softened coefficient $\alpha$. When $\alpha$ is too small, the synchronization error between the two motors is smaller, but the adjusting time is longer; on the contrary, when $\alpha$ is too large, the adjusting time of the two motors is smaller, but the synchronization error is larger. In practice, the synchronous start-up of two motors needs to balance between the synchronization error and the adjusting time so as to achieve the best control effect. In addition, curves $\Delta \omega$ and $t_{\mathrm{s}}$ with respect to $\alpha$ will be different when the given speed or load torque changes. In order to make a multi-motor synchronous control system achieve the best control effect, this paper adopts a fuzzy controller to adjust the output of $\alpha$ automatically.

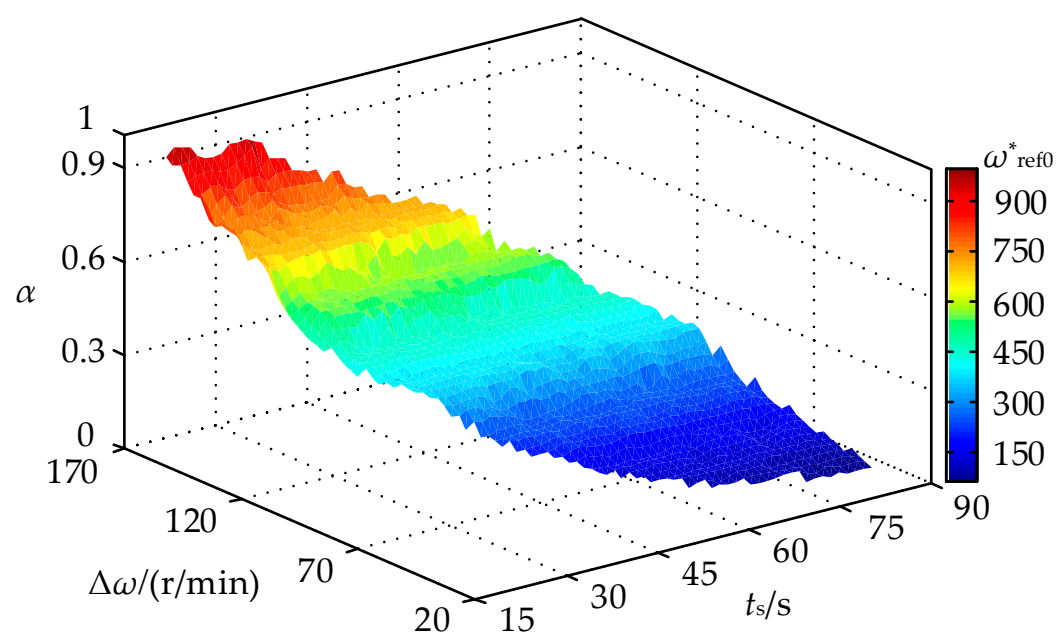

Figure 5. The effect of $\alpha$ on synchronization error and the adjusting time.

The inputs of fuzzy controller are $\omega_{\text {ref }}$ and $T_{\operatorname{Lmax}}$, and the output is $\alpha$. In order to improve the sensitivity of the control, the input and output are quantized by normalized quantization factors [33,34]. The quantized inputs $\omega_{\text {ref }}$ and $T_{\text {Lmax }}$, and the output $\alpha$, belong to seven fuzzy subsets in the universe 
of discourse, namely, \{NB NM NS O PS PM PB\}. NB is Negative Big; NM is Negative Medium; NS is Negative Small; O is Zero; PS is Positive Small; PM is Positive Medium; and PB is Positive Big.

Forty-nine fuzzy rules can be obtained from Mamdani reasoning [35,36], as shown in Table 1. Corresponding input and output membership functions are shown in Figure 6. The three-dimensional rendering of the input and output relations of the fuzzy controller obtained by the fuzzy rules is shown in Figure 7. As can be seen in the figure, the output $\alpha$ of the fuzzy controller decreases, while $\omega_{\text {ref }}$ or $T_{\text {Lmax }}$ increases.

Table 1. Fuzzy control rules. NB: Negative Big; NM: Negative Medium; NS: Negative Small; O: Zero; PS: Positive Small; PM: Positive Medium; PB: Positive Big.

\begin{tabular}{|c|c|c|c|c|c|c|c|}
\hline & NB & NM & NS & ZO & PS & PM & PB \\
\hline NB & $\mathrm{PB}$ & $\overline{\mathrm{PB}}$ & PB & $\mathrm{PB}$ & PM & PS & $\mathrm{ZO}$ \\
\hline NM & $\mathrm{PB}$ & PB & PM & $\mathrm{PM}$ & PS & $\mathrm{ZO}$ & $\mathrm{ZO}$ \\
\hline NS & $\mathrm{PB}$ & $\mathrm{PM}$ & PM & PS & $\mathrm{ZO}$ & $\mathrm{ZO}$ & NS \\
\hline ZO & PM & PS & PS & $\mathrm{ZO}$ & NS & NS & NM \\
\hline PS & PS & $\mathrm{ZO}$ & $\mathrm{ZO}$ & NS & NM & NM & NB \\
\hline PM & $\mathrm{ZO}$ & $\mathrm{ZO}$ & NS & NM & NM & NB & NB \\
\hline PB & $\mathrm{ZO}$ & NS & NM & NB & NB & NB & NB \\
\hline
\end{tabular}
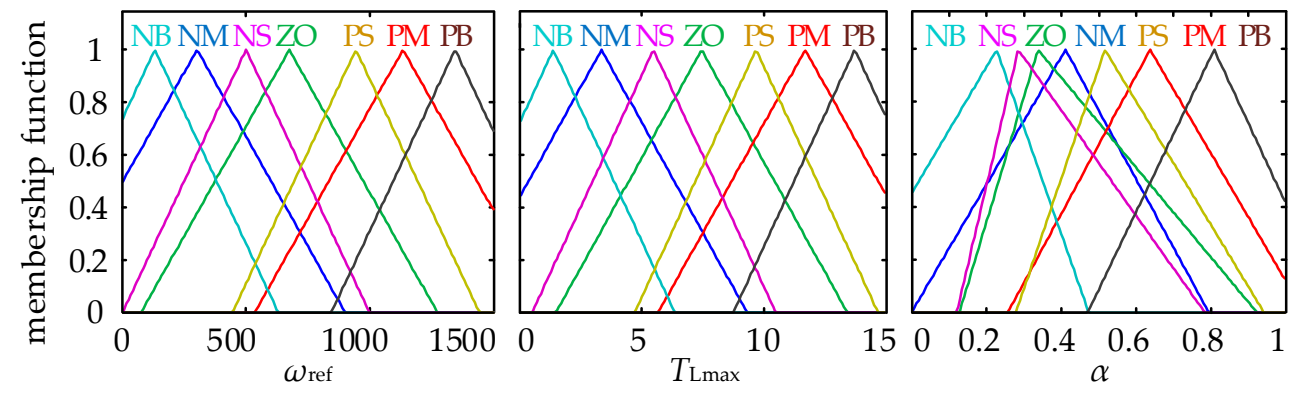

Figure 6. Fuzzy input/output membership function of the fuzzy controller.

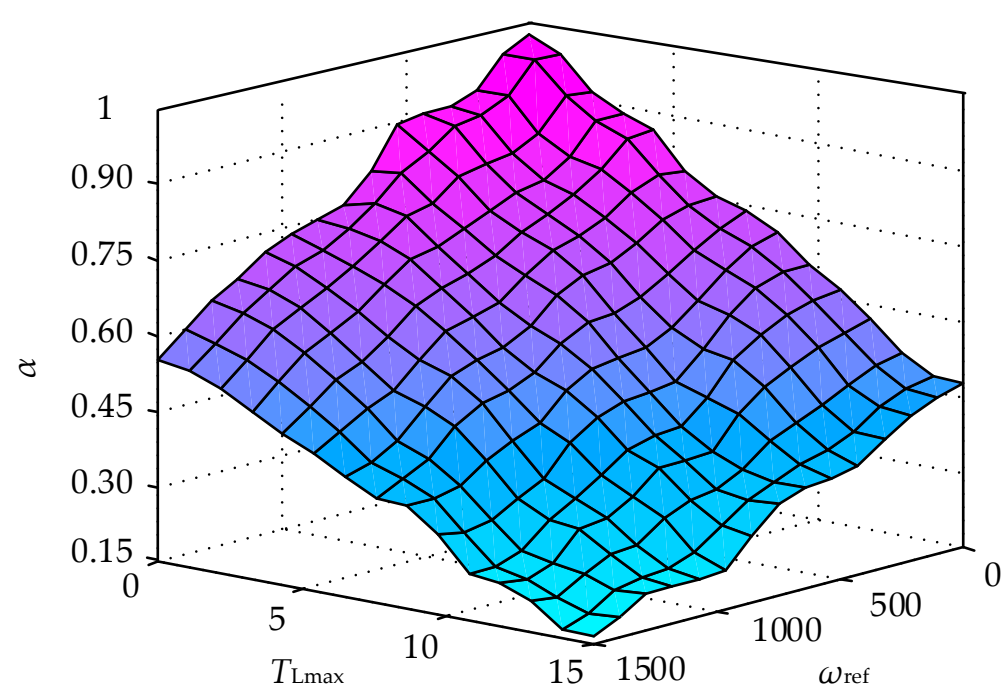

Figure 7. Input and output relationship of the fuzzy controller.

Six combinations are formed by setting $\omega_{\text {ref }}$ as $1000 \mathrm{r} / \mathrm{min}, 800 \mathrm{r} / \mathrm{min}$, and $500 \mathrm{r} / \mathrm{min} ; \mathrm{T}_{\mathrm{L} 1}$ as $5 \mathrm{~N} \cdot \mathrm{m}$ and $15 \mathrm{~N} \cdot \mathrm{m}$; and $T_{\mathrm{L} 2}$ as 0 , respectively. The fuzzy control was used to obtain the value of $\alpha$ and 
the curve of $\omega^{*}$ ref. Figure 8 shows the softened speed under different operating conditions, and Table 2 shows the different operating conditions that correspond to Figure 8.

Table 2. Different operating conditions that correspond to Figure 8.

\begin{tabular}{|c|c|c|c|c|c|c|}
\hline $\begin{array}{ll} & \text { Condition } \\
\text { Variate }\end{array}$ & (1) & (2) & (3) & (4) & (5) & (6) \\
\hline$\omega_{\text {ref }}(r / m i n)$ & 1000 & 800 & 1000 & 800 & 500 & 500 \\
\hline$T_{\text {Lmax }}(\mathrm{N} \cdot \mathrm{m})$ & 15 & 15 & 5 & 5 & 15 & 5 \\
\hline$\alpha$ & 0.27 & 0.31 & 0.35 & 0.45 & 0.4 & 0.7 \\
\hline
\end{tabular}

(1) (3), (2) (4), and (5) (6) correspond to three operating conditions of the same given speed but different load torques; while (1) (2) (5) and (3) (4) (6) correspond to the operating conditions of the same load torque but different speeds. The variation of softened speed $\omega^{*}$ ref can be roughly divided into two stages: the rising stage, and the steady stage, in which the motor speed increases rapidly at the initial stage of starting, and the fuzzy self-adjusting module automatically adjusts the softened speed so that it is on the rise. Then $e_{i}$ decreases, thus shortening the time of $T_{\mathrm{e} i}$ in saturation. Then, $\omega^{*}{ }_{\text {ref }}$ remains unchanged after the motor gradually enters the steady state. First, comparing the working conditions (1) (3), the load torque of the working condition (1) is larger, so the adjusting time of the output speed of the motor is longer. Therefore, the time required for the softened speed of the fuzzy self-adjusting control to reach the maximum value increases correspondingly, so that $t_{1}>t_{3}$, making each motor follow the softened speed trajectory in a better manner. Then, comparing the working conditions (1) (2), because the given speed of (1) is greater than that of (2), the period in which $\omega^{*}$ ref is on the rise under condition (1) is longer, thus $t_{1}>t_{2}$, ensuring that each motor can better follow the trajectory of the softened speed. According to Equation (9), since $\omega_{\max }=0$ at the initial starting time, the output value $\alpha$ of the fuzzy controller is different when the given speed is different. From Equation (9), it can be seen that the values of the softened speeds of two motors are different at the initial starting time. Therefore, by adjusting the softened coefficient according to different operating conditions, the fuzzy self-adjusting control module can make each motor better follow the trajectory of the softened speed. Furthermore, the input of the speed loop controller is reduced, so that the time of electromagnetic torque in the saturation state is shortened. Finally, the purpose of reducing the synchronization error during the start-up is achieved.

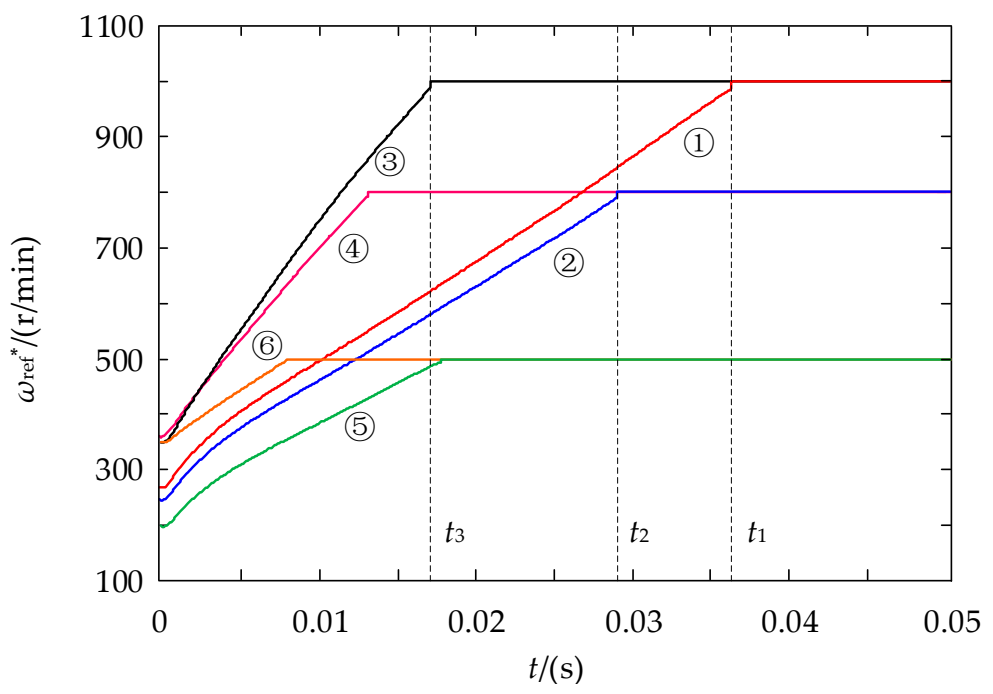

Figure 8. Softened speed under different operating conditions. 


\subsection{The Advanced Synchronization Compensator}

When a load of the motor changes greatly, the fixed gain synchronous compensator will give rise to an excessive fluctuation of speed, and it takes a long time for the fluctuation to be smoothed out. For each motor, the speed fluctuation of any other motor can be regarded as a time-varying interference. In order to eliminate the effect of interference on the output characteristic of the system, corrective control is employed to further improve the adjusting time. The synchronous compensator with anticipatory control is shown in Figure 9.

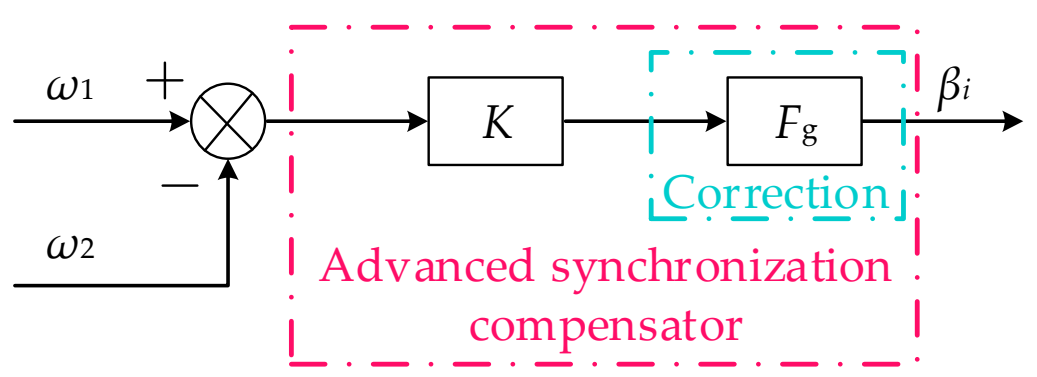

Figure 9. Advanced synchronous compensator.

In Figure 9, $K$ is the synchronization compensation coefficient; and $F_{\mathrm{g}}$ is the correction controller. In order to accelerate the system's dynamic response [37], this paper introduces the classic advanced correction, namely:

$$
F_{\mathrm{g}}(s)=\frac{\eta \cdot T s+1}{T s+1}
$$

where $T$ is advanced time constant; and $\eta$ is attenuation factor and $\eta>1$.

The advanced compensation controller compensates the output speed of its own according to the disturbance level of the other motor. The amount of advancement needed by the system is obtained by using the phase advance characteristic of $F_{\mathrm{g}}$, thus increasing the cut-off frequency, and finally reducing the influence of the disturbance.

The following analysis indicates the influence of the speed fluctuation of the second motor on the first motor in the fuzzy self-adjusting cross-coupling control structure. As shown in Figure 3, the output speed $\omega_{2}$ of the second motor is taken as the input, and the output speed $\omega_{1}$ of the first motor is taken as the output. The transfer function in this case is:

$$
\frac{\omega_{1}(s)}{\omega_{2}(s)}=\frac{K F_{\mathrm{g}}(s) F(s) G(s)}{1+\left[1+K F_{\mathrm{g}}(s)\right] F(s) G(s)}
$$

A Bode diagram of phase-frequency characteristics and amplitude-frequency characteristics when $K=2$ is shown in Figure 10. In order to facilitate the comparison with the traditional cross-coupling control structure, the transfer function of the traditional cross-coupling structure is deduced as:

$$
\frac{\omega_{1 \operatorname{tra}}(s)}{\omega_{2 \operatorname{tra}}(s)}=\frac{K F(s) G(s)}{1+(1+K) F(s) G(s)}
$$

Figure 10 also shows the Bode diagram of the amplitude-frequency characteristics and phase-frequency characteristics of the traditional structure. As can be seen from the figure, the fuzzy self-adjusting cross-coupling control structure increases the cut-off frequency and improves the system's dynamic response compared with the traditional cross-coupling control structure. The phase margin increases, and the stability of the system is improved. 


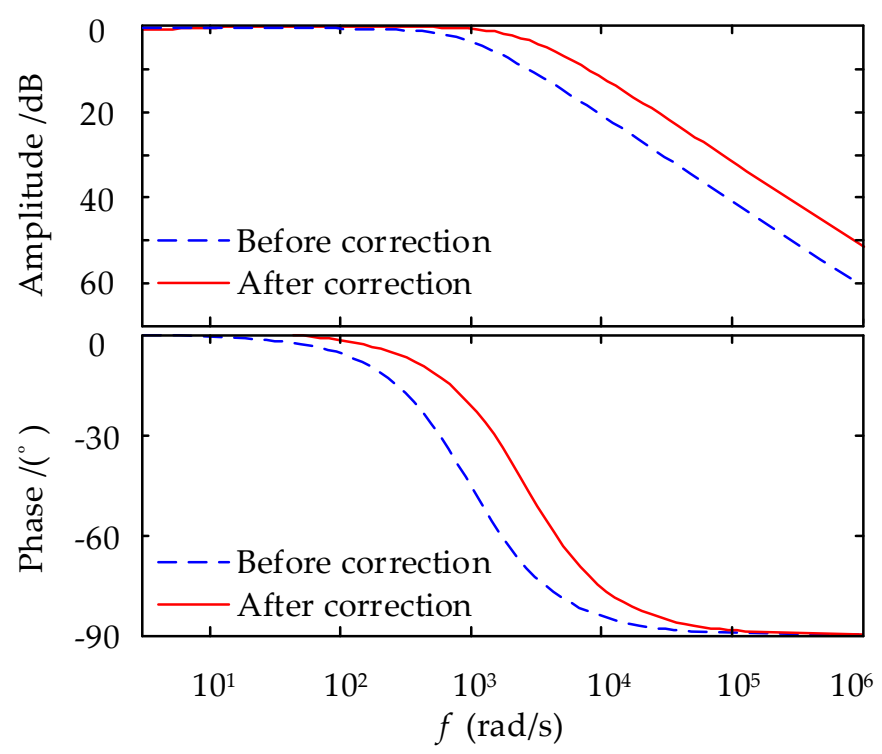

Figure 10. Bode plots characteristic of the controlled object before and after correction.

\section{Performance Analysis of Fuzzy Self-adjusting Cross-Coupling Control}

\subsection{Synchronization Performance Analysis during the Start-Up of Motors with Load}

To simplify the analysis, it is assumed that the load torque of the first motor is $T_{\mathrm{L} 1}>0$, and the second motor starts without load. Therefore, for the output speeds of the first motor and the second, it holds that $\omega_{1}<\omega_{2}$. In Figure 11, $e_{i}$ is the input of the $i$ th $(i=1,2)$ motor's speed loop controller; and $\Delta \omega_{i}$ is the tracking error of the $i$ th motor. Setting the rated torque as $T_{\mathrm{N}}$, then, the saturation value equals $1.2 T_{\mathrm{N}}$.
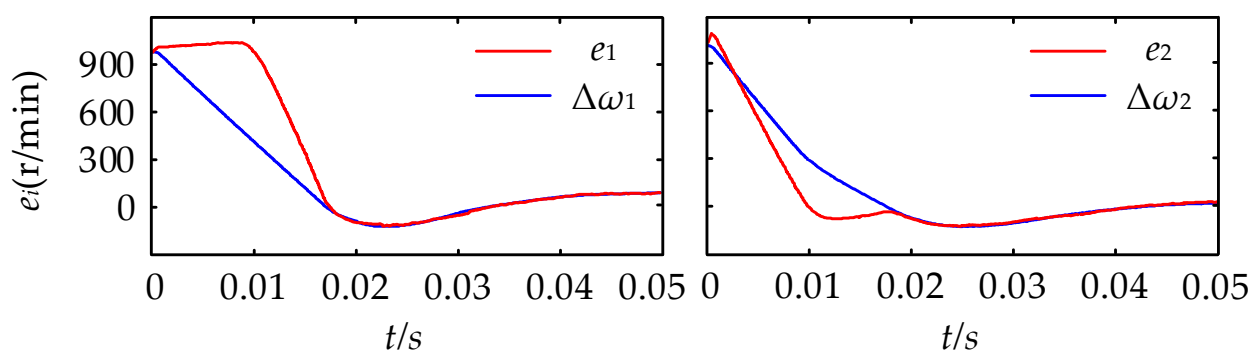

(a)
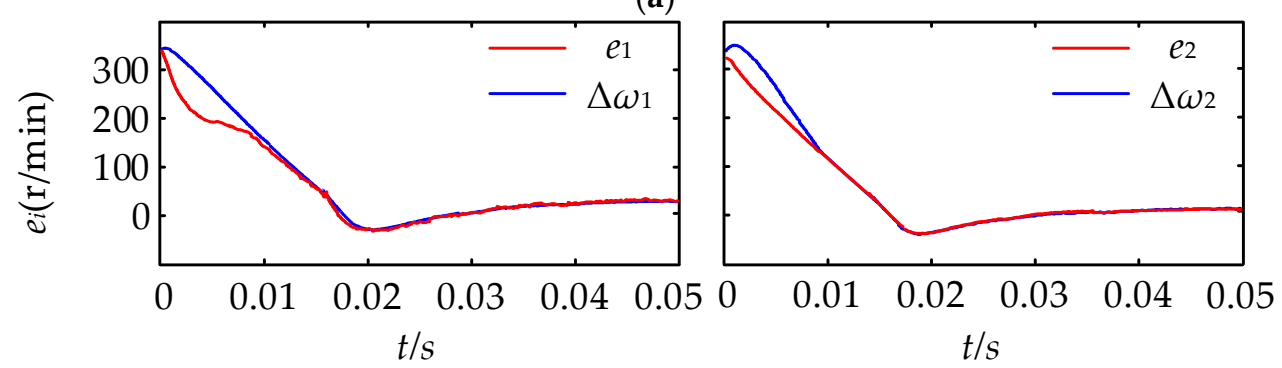

(b)

Figure 11. Input $e_{1}$ of the speed loop controller of the two structures: (a) $e_{1}$ in the traditional cross-coupling control structure; (b) $e_{1}$ in the fuzzy self-adjusting cross-coupling control structure.

It can be seen from Figure 11a that in the traditional cross-coupling control structure, for the load motor, it holds that $e_{1}>\Delta \omega_{1}$, indicating that the compensation value $\beta_{1}<0$ and $e_{1}$ during the 
start-up of the motors with load is large. As a result, the output $T_{\mathrm{u} 1}$ of the controller corresponding to the input $e_{1}$ is far greater than the saturation value, so $T_{\mathrm{e} 1}$ is equal to $1.2 T_{\mathrm{N}}$. The compensation value basically does not work. For the initial value of the no-load motor during starting, it holds that $e_{2}>\Delta \omega_{2}$; the compensation value still does not work. Only when $\beta_{2}$ increases to a certain value does the compensation value begin to play a compensatory role.

In Figure $11 \mathrm{~b}$, the load motor satisfies $e_{1}<\Delta \omega_{1}$, indicating that the compensation value $\beta_{1}>0$, and the advanced synchronous compensator compensates for the speed. The advanced synchronous compensator of the no-load motor also compensates for the speed.

Regarding the early stages during the start-up, the controller of each motor is working in the nonlinear region. Ignoring the integral action of the controller, the input $e_{i}(i=1,2)$ of the speed loop controller with load in the starting process is:

$$
\begin{aligned}
& e_{i}=\Delta \omega_{i}-\beta_{i}=\omega_{\text {ref }}^{*}-\omega_{i}-\beta_{i}=\left[\alpha \omega_{\text {ref }}+(1-\alpha)\left(\omega_{i}-\Delta \omega\right)-\omega_{i}\right]-K\left(\omega_{i}-\omega_{j}\right) F_{\mathrm{g}} \\
& =\alpha\left(\omega_{\text {ref }}-\omega_{i}\right)-(1-\alpha) \Delta \omega-K F_{\mathrm{g}} \Delta \omega \\
& =\alpha \Delta \omega_{i}-\left[K F_{\mathrm{g}}+(1-\alpha)\right] \Delta \omega
\end{aligned}
$$

Similarly, the input of the speed loop controller in the traditional cross-coupling control structure is:

$$
e_{i(\text { tra })}=\Delta \omega_{i}-K \Delta \omega
$$

Comparing Equation (13) with (14), it should be noted that in the starting process of the fuzzy self-adjusting cross-coupling control structure, because $0<\alpha<1$ and $\eta>1$, the coefficient before the first term $\Delta \omega_{i}$ of Equation (13) is reduced; that is, the tracking proportional coefficient decreases. Further, the coefficient before the second $\Delta \omega$ increases; that is, the synchronization proportional coefficient increases.

In summary, in the multi-motor starting process, compared with the traditional cross-coupling control structure, the tracking error of the fuzzy self-adjusting cross-coupling control structure decreases, and the synchronous compensator output increases simultaneously. Hence, the input of the speed loop controller decreases. Therefore, the time for $T_{\mathrm{u} 1}$ to be saturated is shortened, and the synchronization error is thus reduced.

When the controller of each motor works in the linear region, the difference of accelerations between two motors in the fuzzy self-adjusting cross-coupling control structure is:

$$
\begin{aligned}
& a_{1}-a_{2} \\
& =\frac{f_{\mathrm{c}} J_{1}\left[\alpha \omega_{\mathrm{ref}}+(1-\alpha) \omega_{\max }-\omega_{1}\right]}{J_{1}}-\frac{K f_{\mathrm{c}} J_{1}\left(\omega_{1}-\omega_{2}\right)}{J_{1}}+\frac{K f_{\mathrm{c}} J_{2}\left(\omega_{2}-\omega_{1}\right)}{J_{2}}-\frac{f_{\mathrm{c}} J_{2}\left[\alpha \omega_{\mathrm{ref}}+(1-\alpha) \omega_{\max }-\omega_{2}\right]}{J_{2}} \\
& =f_{\mathrm{c}}(1+K)\left(\omega_{2}-\omega_{1}\right)
\end{aligned}
$$

From Equation (15), it should be noted that the acceleration difference between two motors is independent of $\alpha$; that is, changing the softened coefficient $\alpha$ will not influence the synchronization performance of the system in the working area of the linear zone.

\subsection{Synchronization Performance Analysis of Steady State with Sudden Changes of Load}

In this section, the synchronization performance of the steady state with sudden changes of loads in a fuzzy self-adjusting cross-coupling control structure is analyzed. The $i$ th motor output speed is:

$$
\omega_{i}=\frac{\omega_{\text {ref }} F G-T_{\mathrm{L} i} G_{i}+K F_{\mathrm{g}} F G\left(\omega_{1}+\omega_{2}\right)}{1+\left(1+2 K F_{\mathrm{g}}\right) F G}
$$

Derived from Equation (16), the synchronization error between two motors can be expressed as:

$$
\Delta \omega=\omega_{1}-\omega_{2}=\frac{T_{\mathrm{L} 2} G_{2}-T_{\mathrm{L} 1} G_{1}}{1+\left(1+2 K F_{\mathrm{g}}\right) F G}
$$


Similarly, the synchronization error of two motors in the traditional cross-coupling control structure is:

$$
\Delta \omega_{\text {tra }}=\omega_{1}-\omega_{2}=\frac{T_{\mathrm{L} 2} G_{2}-T_{\mathrm{L} 1} G_{1}}{1+(1+2 K) F G}
$$

From the above analysis, it should be noted that $\eta>1$, therefore, $1-F_{\mathrm{g}}<0$. Compared with the traditional cross-coupling control structure, the $\Delta \omega$ of a fuzzy self-adjusting cross-coupling control structure decreases obviously; that is, the synchronization error between two motors in steady state with sudden changes of load decreases.

\section{Experiments and Analysis}

\subsection{Experimental System and Parameter Selection}

To verify the effectiveness of the fuzzy self-adjusting cross-coupling control structure, the PMSM speed control system experimental platform is constructed, as shown in Figure 12. The hardware system is mainly composed of two PMSMs. The PMSMs used in this paper are surface-mounted. One motor is connected to the magnetic powder brake, and the other is connected to the load motor, which is interlinked over a resistance box. The controlling circuit features mainly include a main control panel, power circuit, drive circuit, voltage, current sensors, and so on. The DSP chip TMS320F28335 produced by TI is used as the core in the main control panel. The power devices use Mitsubishi's IPM module PS21867, and the switching frequency is $5 \mathrm{kHz}$. The parameters of two motors are shown in Table 3.

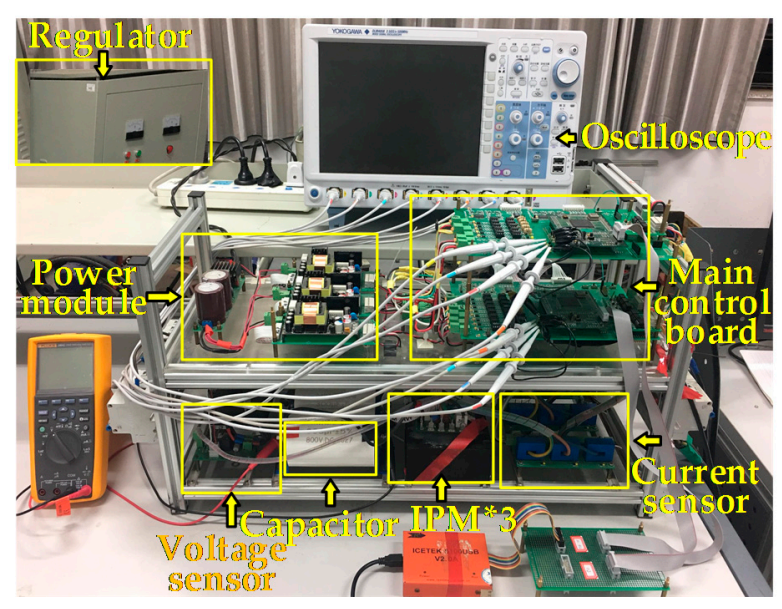

(a)

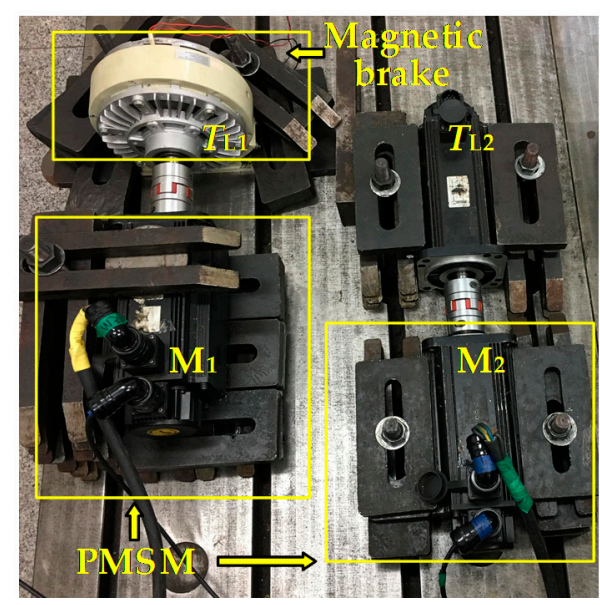

(b)

Figure 12. Experiment system: (a) The experimental platform for the synchronous speed control system; (b) System of PMSMs and the magnetic powder brake.

Table 3. Experiment parameters of permanent magnet synchronous motors (PMSMs).

\begin{tabular}{cccccc}
\hline Motors & $\boldsymbol{T}_{\mathrm{N}}(\mathrm{N} \cdot \mathrm{m})$ & $\boldsymbol{J}\left(\mathbf{k g} \cdot \mathbf{m}^{2}\right)$ & $n_{\mathrm{N}}(\mathbf{r} / \mathbf{m i n})$ & $p$ & $\boldsymbol{P}_{\mathrm{N}}(\mathbf{k W})$ \\
\hline $\mathrm{M}$ & 15 & $2.72 \times 10^{-3}$ & 1500 & 2 & 2.3 \\
\hline
\end{tabular}

\subsection{Performance Comparison of Two Structures During the Start-Up of Motors with Load}

The experimental parameters are set as follows: initially, the two motors start at a given speed of $500 \mathrm{r} / \mathrm{min}$. Motor 1 is connected to the magnetic brake, and Motor 2 is connected to a load motor. The torque of the magnetic brake is $8 \mathrm{~N} \cdot \mathrm{m}$, and the load motor is no-load. The rated torque is $T_{\mathrm{N}}$, and the saturation value of the speed loop controller is set as $1.2 T_{\mathrm{N}}$. A performance comparison of the synchronization error and output speed between the two structures during the start-up of motors 
with load are shown in Figures 13 and 14. In the figure, $t_{\mathrm{s}}$ is the adjusting time, and $t_{\mathrm{p}}$ is the peak time. The electromagnetic torque outputs of the first and second motor during the start-up are shown in Figures 15 and 16, respectively. Performances of the traditional cross-coupling control structure (abbreviated as traditional structure hereafter) are shown in Figure 13a of every figures below, and performances of the fuzzy self-adjusting cross-coupling control structure (abbreviated as improved structure hereafter) are shown in Figure 13b of every figures below.

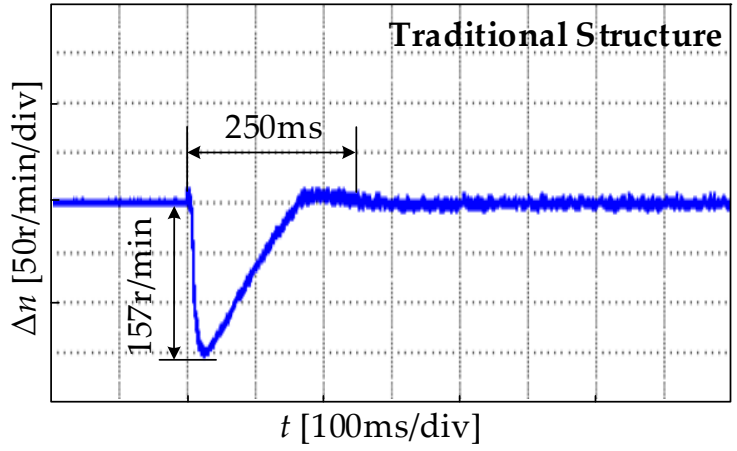

(a)

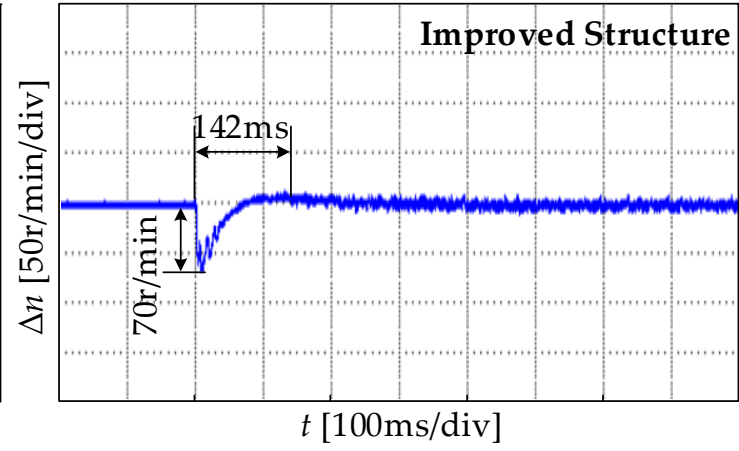

(b)

Figure 13. Synchronization error during the start-up of motors with load: (a) Synchronization error in the traditional structure; (b) Synchronization error in the improved structure.

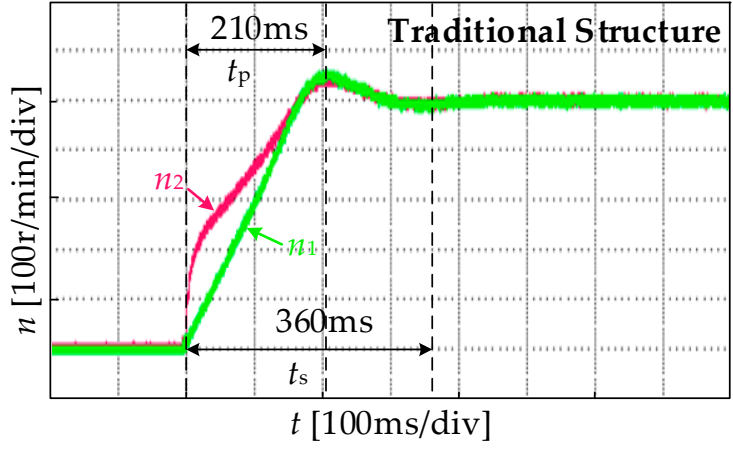

(a)

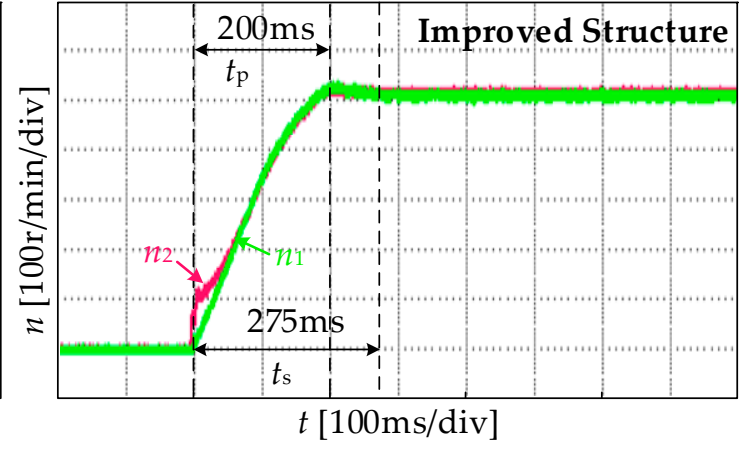

(b)

Figure 14. Output speed during the start-up of motors with load: (a) Output speed in the traditional structure; (b) Output speed in the improved structure.

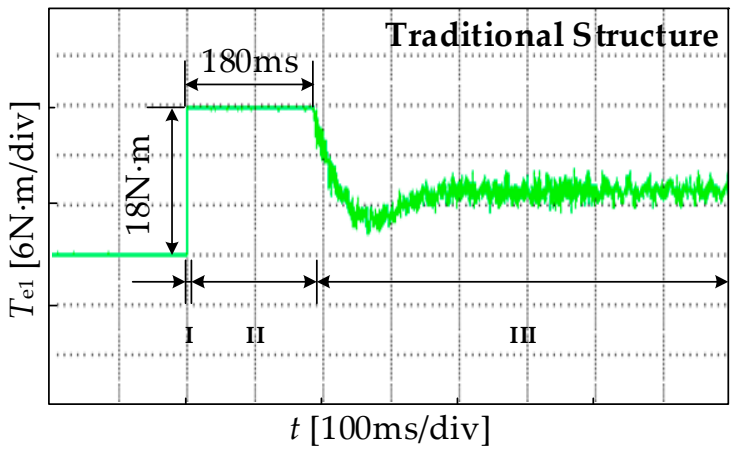

(a)

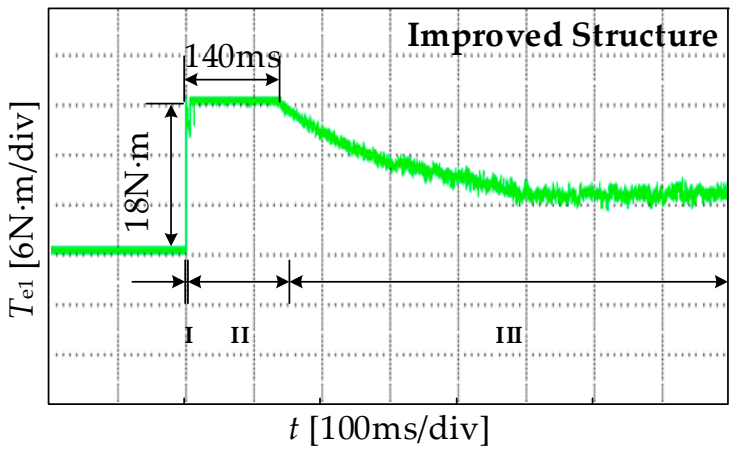

(b)

Figure 15. Electromagnetic torque output of the first motor during the start-up of motors with load: (a) Electromagnetic torque output in the traditional structure; (b) Electromagnetic torque output in the improved structure. 

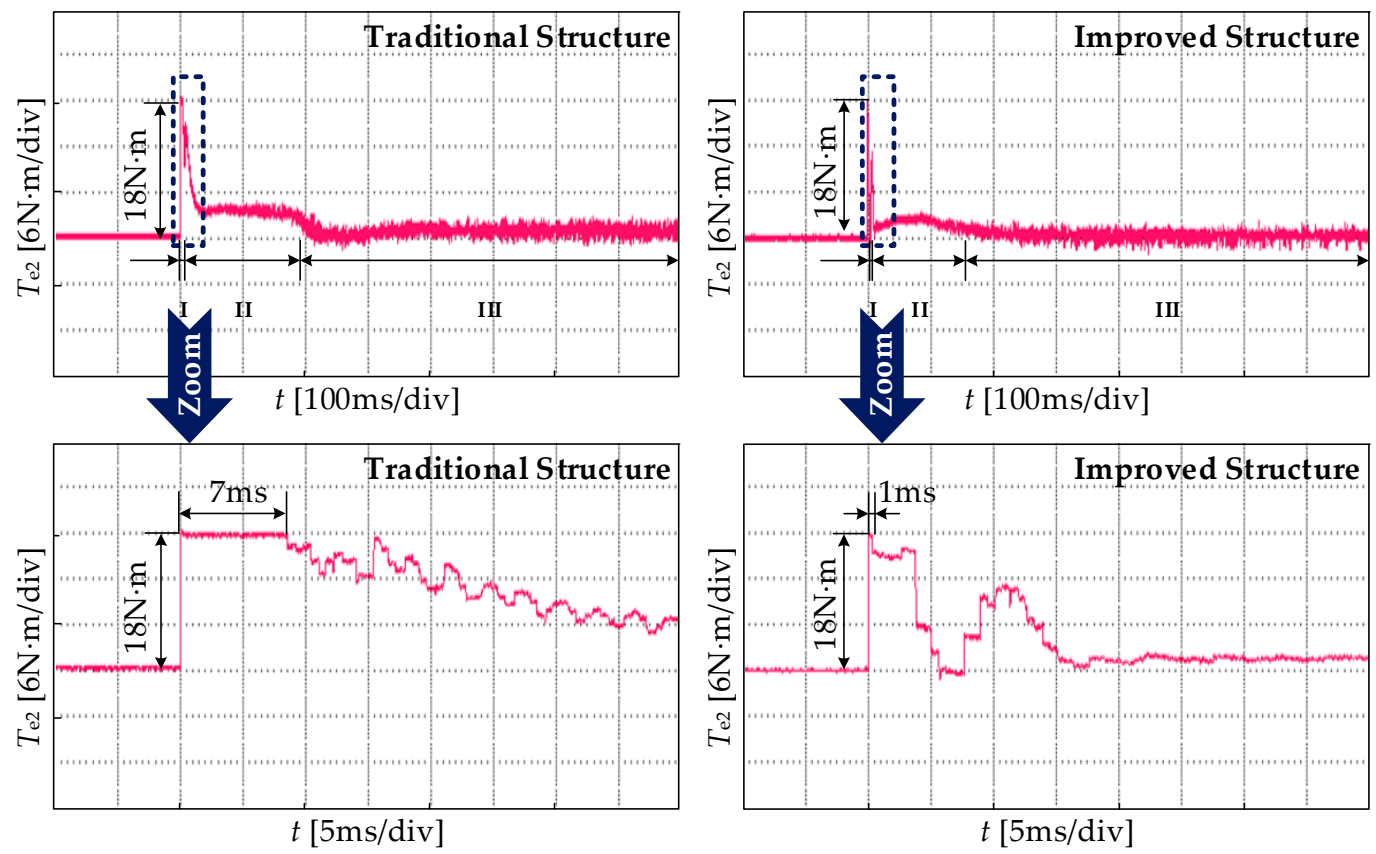

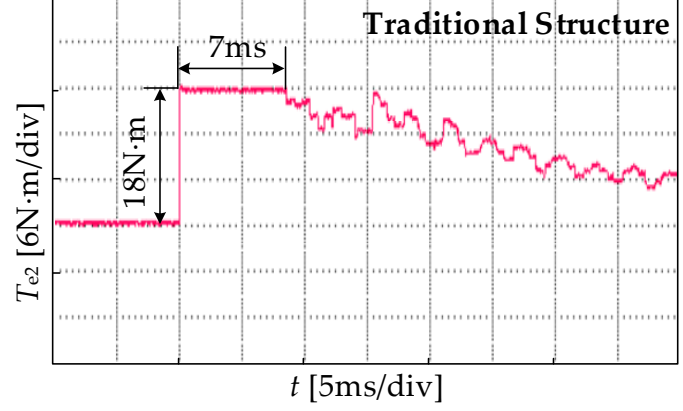

(a)

(b)

Figure 16. Electromagnetic torque output of the second motor during the start-up of motors with load: (a) Electromagnetic torque output in the traditional structure; (b) Electromagnetic torque output in the improved structure.

As can be seen from Figure 13, the maximum synchronization error of the improved structure reduces from $157 \mathrm{r} / \mathrm{min}$ to $70 \mathrm{r} / \mathrm{min}$, which is a reduction of $55 \%$ compared with the traditional structure. Meanwhile, the dynamic response of synchronization error increases by $43 \%$. In Figure 14, the adjusting time reduces from $360 \mathrm{~ms}$ to $275 \mathrm{~ms}$, which is a $23 \%$ reduction; and the peak time reduces by $4.8 \%$.

From the above experiments, it should be noted that the starting process of the motor is divided into three stages. In Figures 15a and 16a, the electromagnetic torque outputs of the two motors are saturated within $7 \mathrm{~ms}$ in the first stage, and the synchronous compensator does not work at all. In the second stage, the electromagnetic torque output of Motor 1 is still in saturation. As a result of the compensation value, Motor 2 enters the linear region, and its working time is $173 \mathrm{~ms}$. In the third phase, both of the motors run in the linear working region under the action of compensation. In Figures 15b and 16b, namely, in the improved structure, the working time of the first stage is shortened by $6 \mathrm{~ms}$. Since the control period of the system is $0.4 \mathrm{~ms}$, it enters the linear work area 15 times in advance; in stage II, the electromagnetic torque output of Motor 1 stays in saturation for $139 \mathrm{~ms}$, which a $19 \%$ reduction, and is why the synchronization error significantly reduces.

\subsection{Performance Comparison of Two Structures in Steady State with Sudden Changes of Load}

The given speed is $400 \mathrm{r} / \mathrm{min}$, and the two motors both start without load. A sudden load of $10 \mathrm{~N} \cdot \mathrm{m}$ is applied to Motor 1 in the stable operation. The output speed of each motor and synchronization error of the two structures are shown in Figures 17 and 18, respectively.

As can be seen from Figure 17, the maximum synchronous error between two motors reduces from $128 \mathrm{r} / \mathrm{min}$ to $95 \mathrm{r} / \mathrm{min}$, which is a decrease of $25.7 \%$, compared with the traditional structure. The convergence speed of synchronization error increased by $49 \%$.

In Figure 18, the adjusting time of the speed is shortened by $39 \%$, the tracking error is reduced from $74 \mathrm{r} / \mathrm{min}$ to $70 \mathrm{r} / \mathrm{min}$-almost unchanged—and the response time of the tracking error reduces from $69 \mathrm{~ms}$ to $60 \mathrm{~ms}$. 
To summarize, the improved structure proposed in this paper not only improves the synchronization performance and dynamic response between two motors in the starting process, it also improves the synchronization performance of motors when the steady state is interrupted by a sudden change of load.

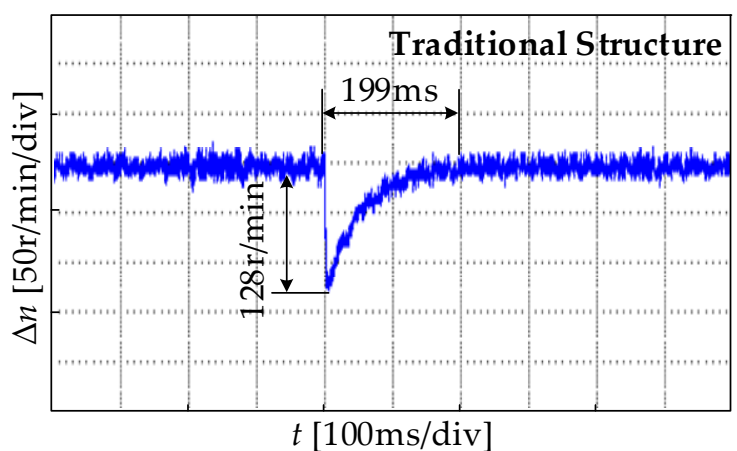

(a)

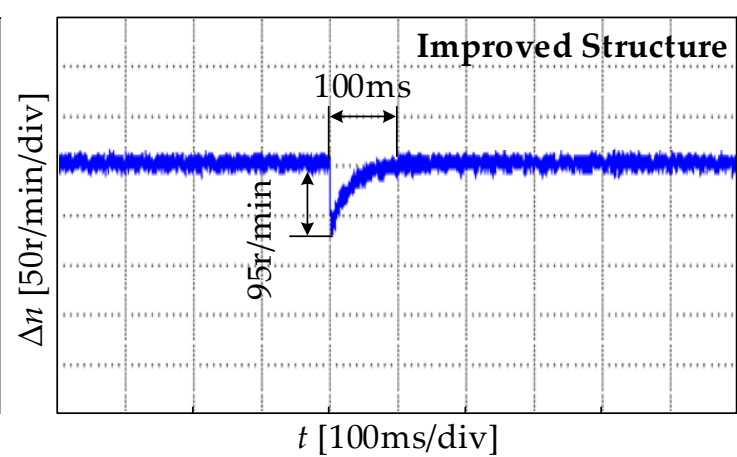

(b)

Figure 17. Synchronization error of motors under sudden changes of a load during steady operation: (a) Synchronization error in the traditional structure; (b) Synchronization error in the improved structure.
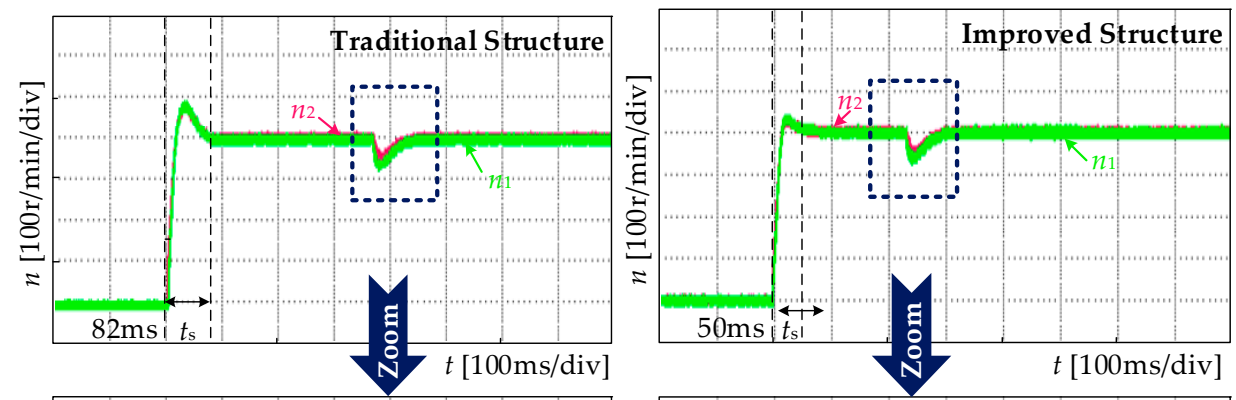

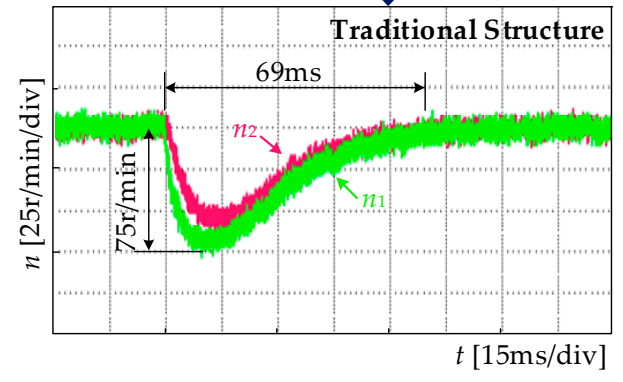

(a)

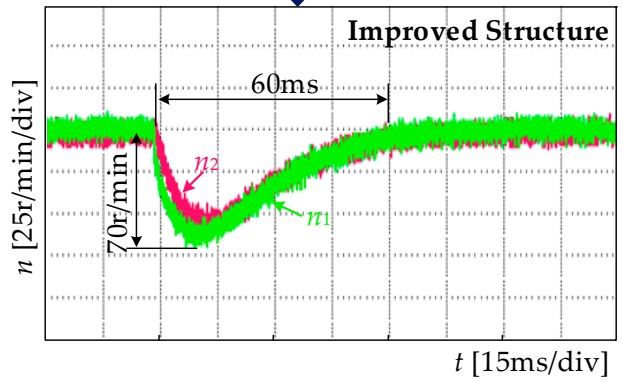

(b)

Figure 18. Speed output of motors under sudden changes of a load during steady operation: (a) Speed output in the traditional structure; (b) Speed output in the improved structure.

\section{Conclusions}

Aiming at the shortcomings of the cross-coupling control structure, which has a large synchronization error and a long starting time in the multi-motor system during the start-up of motors with load, this paper presents a new coupling control structure with a fuzzy self-adjusting filter and an advanced synchronization compensator.

1. The structure adopts the mode selector to switch between working modes of the fuzzy controller. It automatically adjusts the softened coefficient according to different given speeds and maximum load torques, and then adjusts the softened speed so that each motor follows the trajectory of the 
softened speed in the starting process. These adjustments effectively reduce the synchronization error during the start-up of motors with load. At the same time, the advanced synchronization compensator is put forward to improve the system's dynamic response.

2. The synchronization performance of the fuzzy self-adjusting cross-coupling control structure under the steady state with a sudden change of load is analyzed. The experimental results show that the structure proposed in this paper can improve the system synchronization performance and dynamic response both in the starting process, and in the steady state with a sudden change of load.

Acknowledgments: This work is supported by The National Natural Science Foundation of China (No. 51777135), The Key Project in the Science \& Technology Pillar Program of Tianjin (No. 16YFZCSF00580).

Author Contributions: Wei Chen, Jiaojiao Liang and Tingna Shi put forward the idea and designed the simulation and the experiments; Jiaojiao Liang performed the simulation and the experiments; all authors analyzed the results; all authors contributed to the writing of the paper; Jiaojiao Liang and Tingna Shi reviewed and edited the manuscript.

Conflicts of Interest: The authors declare no conflict of interest.

\section{References}

1. Chen, W.; Wu, Y.; Du, R.; Chen, Q.; Wu, X. Speed tracking and synchronization of a dual-motor system via second order sliding mode control. Math. Prob. Eng. 2013, 2013. [CrossRef]

2. Jiang, C.; Chau, K.T.; Liu, C.; Lee, C.H.T. An overview of resonant circuits for wireless power transfer. Energies 2017, 10, 894. [CrossRef]

3. Liu, M.; Gu, F.; Huang, J.; Wang, C.; Cao, M. Integration design and optimization control of a dynamic vibration absorber for electric wheels with in-wheel motor. Energies 2017, 10, 2069. [CrossRef]

4. Li, X.; Chau, K.T.; Wang, Y. Modeling of a field-modulated permanent-magnet machine. Energies 2016, 9, 1078. [CrossRef]

5. Wang, Q.; He, F. The synchronous control of multi-motor drive control system with floating compensation. In Proceedings of the 2016 12th World Congress on Intelligent Control and Automation (WCICA), Guilin, China, 12-15 June 2016. [CrossRef]

6. Zhang, C.; Jia, L.; Xiao, Y.; He, J.; Xu, C. Virtual line-shafting control for permanent magnet synchronous motor systems using sliding-mode observer. IET Control Theory Appl. 2015, 9, 456-464. [CrossRef]

7. Lin, F.J.; Hung, Y.C.; Ruan, K.C. An intelligent second-order sliding-mode control for an electric power steering system using a wavelet fuzzy neural network. IEEE Trans. Fuzzy Syst. 2014, 22, 1598-1611. [CrossRef]

8. Shi, T.; Liu, H.; Geng, Q.; Xia, C. Improved relative coupling control structure for multi-motor speed synchronous driving system. IET Electr. Power Appl. 2016, 10, 451-457. [CrossRef]

9. Luo, Y.; Liu, C.; Yu, F.; Lee, C.H.T. Design and evaluation of an efficient three-phase four-leg voltage source inverter with reduced IGBTs. Energies 2017, 10, 530. [CrossRef]

10. Liu, X.; Lin, Q.; Fu, W. Optimal design of permanent magnet arrangement in synchronous motors. Energies 2017, 10, 1700. [CrossRef]

11. Liu, M.; Gu, F.; Zhang, Y. Ride comfort optimization of in-wheel-motor electric vehicles with in-wheel vibration absorbers. Energies 2017, 10, 1647. [CrossRef]

12. Chen, C.S.; Chen, L.Y. Robust cross-coupling synchronous control by shaping position commands in multiaxes system. IEEE Trans. Ind. Electron. 2012, 59, 4761-4773. [CrossRef]

13. Chen, S.L.; Yang, J.H. Contouring control of biaxial systems with optimal and adaptive cross coupling controller. In Proceedings of the 2015 IEEE International Conference on Automation Science and Engineering (CASE), Suzhou, China, 23-25 October 2015. [CrossRef]

14. Corapsiz, M.; Erenturk, K. Trajectory tracking control and contouring performance of three dimensional CNC. IEEE Trans. Ind. Electron. 2016, 63, 2212-2220. [CrossRef]

15. Li, L.; Li, W.; Li, D.; Li, J.; Fan, Y. Research on strategies and methods suppressing permanent magnet demagnetization in permanent magnet synchronous motors based on a multi-physical field and rotor multi-topology structure. Energies 2018, 11, 40. [CrossRef] 
16. Su, K.H.; Cheng, M.Y. Contouring accuracy improvement using cross-coupled control and position error compensator. Int. J. Mach. Tools Manuf. 2008, 48, 1444-1453. [CrossRef]

17. Zhao, D.Z.; Li, C.W.; Ren, J. Speed synchronisation of multiple induction motors with adjacent cross-coupling control. IET Control Theory Appl. 2010, 4, 119-128. [CrossRef]

18. Zhu, X.; Yao, B.; Tao, G.; Wang, Q.; Cao, J. Adaptive robust synchronous control of a individual metering dual-cylinder pneumatic system with composite parallel method. In Proceedings of the 2014 IEEE/ASME International Conference on Advanced Intelligent Mechatronics, Besancon, France, 8-11 July 2014. [CrossRef]

19. Chen, Z.; He, J.; Zheng, Y.; Song, T.; Deng, Z. An optimized feedforward decoupling PD register control method of roll-to-roll web printing systems. IEEE Trans. Autom. Sci. Eng. 2016, 13, 274-283. [CrossRef]

20. Chen, W.; Wang, D.; Geng, Q.; Xia, C. Robust adaptive cross-coupling position control of biaxial motion system. Sci. China Technol. Sci. 2015, 59, 680-688. [CrossRef]

21. Anderson, R.G.; Meyer, A.J.; Valenzuela, M.A.; Lorenz, R.D. Web machine coordinated motion control via electronic line-shafting. IEEE Trans. Ind. Appl. 2001, 37, 247-254. [CrossRef]

22. Koren, Y. Cross-coupled biaxial computer control for manufacturing systems. J. Dyn. Syst. Meas. Control 1980, 102, 265-272. [CrossRef]

23. Gu, X.; Hu, S.; Shi, T.; Geng, Q. Multi-parameter decoupling on-line identification of permanent magnet synchronous motor based on neural network. Trans. China Electrotech. Soc. 2015, 30, 114-121. [CrossRef]

24. Zhang, H.; Wang, P.; Han, B.; Cheng, J. Rotor position measuring method for magnetic levitation high speed PMSM based on fuzzy sliding mode observer. Trans. China Electrotech. Soc. 2014, 29, 148-154. [CrossRef]

25. Liu, G.; Zhang, J.; Zhao, W.; Zhang, Y.; Jiang, Y. Internal model control based on support vector machines generalized inverse for two-motor variable frequency system applications. Proc. CSEE 2011, 31, 85-91. [CrossRef]

26. Lee, C.H.T.; Chau, K.T.; Cao, L. Development of reliable gearless motors for electric vehicles. IEEE Trans. Magn. 2017, 53, 1-8. [CrossRef]

27. Yepes, A.G.; Vidal, A.; Lopez, O.; Doval-Gandoy, J. Evaluation of techniques for cross-coupling decoupling between orthogonal axes in double synchronous reference frame current control. IEEE Trans. Ind. Electron. 2014, 61, 3527-3531. [CrossRef]

28. Zhao, X.; Zhao, J. Cross-coupled complementary sliding mode control for precision direct-drive gantry system. Trans. China Electrotech. Soc. 2015, 30,7-12. [CrossRef]

29. Huang, Z.; Chen, J. Analysis and implementation of permanent magnet synchronous motor control starting process for electric vehicle. Electr. Mach. Control Appl. 2015, 42, 60-64. [CrossRef]

30. Harnefors, L.; Saarakkala, S.E.; Hinkkanen, M. Speed control of electrical drives using classical control methods. In Proceedings of the 2011 IEEE Energy Conversion Congress and Exposition, Phoenix, AZ, USA, 17-22 September 2011. [CrossRef]

31. Zhao, X.; Zhao, J.; Li, H. Robust tracking control for direct drive XY table based on GPC and DOB. Trans. China Electrotech. Soc. 2015, 30, 150-154. [CrossRef]

32. Tian, L.; Zhao, J.; Sun, J. Sensorless control of interior permanent magnet synchronous motor in low-speed region using novel adaptive filter. Energies 2016, 9, 1084. [CrossRef]

33. Li, S.; Gu, H. Fuzzy adaptive internal model control schemes for PMSM speed-regulation system. IEEE Trans. Ind. Inform. 2012, 8, 767-779. [CrossRef]

34. Zhou, J.; Zhao, Z.; Zhang, C.; Li, C.; Xu, Y. A real-time accurate model and its predictive fuzzy PID controller for pumped storage unit via error compensation. Energies 2017, 11, 35. [CrossRef]

35. Shiau, J.K.; Wei, Y.C.; Lee, M.Y. Fuzzy controller for a voltage-regulated solar-powered MPPT system for hybrid power system applications. Energies 2015, 8, 3292-3312. [CrossRef]

36. Liu, D.; Cui, Y.; Zhao, X.; Chen, M. Fuzzy control of speed of permanent magnet synchronous motor based on backstepping control. Trans. China Electrotech. Soc. 2014, 29, 38-44. [CrossRef]

37. Zhang, D.; Chen, Y.; Ai, W.; Zhou, Z. A precision fuzzy control method of permanent magnetic linear motors. Trans. China Electrotech. Soc. 2007, 22, 64-68. [CrossRef]

(C) 2018 by the authors. Licensee MDPI, Basel, Switzerland. This article is an open access article distributed under the terms and conditions of the Creative Commons Attribution (CC BY) license (http:/ / creativecommons.org/licenses/by/4.0/). 